Research Article

\title{
Similar Materials and Engineering Application of Cemented Sand and Gravel Dam Model
}

\author{
Qihui Chai,, ${ }^{1,2}$ Zongkun Li, ${ }^{1}$ Juan Wang ${ }^{1},{ }^{1}$ Zelin Ding, ${ }^{2}$ and Meiju Jiao' \\ ${ }^{1}$ School of Water Conservancy Engineering, Zhengzhou University, Zhengzhou 450001, China \\ ${ }^{2}$ School of Water Resources, North China University of Water Resources and Electric Power, \\ Zhengzhou 450045, China \\ Correspondence should be addressed to Juan Wang; wangjuan@zzu.edu.cn
}

Received 6 March 2020; Revised 17 June 2020; Accepted 30 June 2020; Published 18 August 2020

Academic Editor: Yifeng Ling

Copyright (c) 2020 Qihui Chai et al. This is an open access article distributed under the Creative Commons Attribution License, which permits unrestricted use, distribution, and reproduction in any medium, provided the original work is properly cited.

\begin{abstract}
This paper takes the cemented sand and gravel dam (CSGD) in Shoukoubao reservoir as the prototype to introduce in detail the similarity principle of model test and describe the selection steps of materials for CSG model. It has developed similar materials for CSGD model by mixing coarse sand, barite powder, gypsum powder, cement, and iron powder so as to provide reference for CSGD model test in the future. The dam model test has studied the stress distribution and displacement deformation of the dam during construction and normal operation, in order to provide experimental support for the study of failure mechanism of the CSGD and facilitate the design and construction of dams of this kind. The stress level of the body and the foundation of the model dam varied from $1 / 9$ to $1 / 17$ of the designed compressive strength of dam material. The results showed that CSGD is a safe new type of dams.
\end{abstract}

\section{Introduction}

Reservoir dams are the basis and carrier of water conservancy and hydropower development. They play an irreplaceable role in the comprehensive utilization of water and hydropower resources. They have increasingly important role in supporting the sustainable development of China's social economy [1]. According to the first national water resources census, which was carried out from 2010 to 2012, China had 98,002 reservoir dams. Among the 3,000 dams that had collapsed in China, 98\% were earth-rock dams. Earth-rock dams are easily overtopped, which leads to dam breaking. By contrast, concrete dams are expensive to build with overly high material stress. Therefore, it is necessary to find an inexpensive solution so as to build a new type of dams that will not collapse even if overtopped. Such a solution should not only apply to new dams but also become a new technical support for strengthening existing dams. Cemented sand and gravel dam (CSGD) is developed based on two construction techniques: roller compacted concrete dam (RCCD) and concrete face rockfill dam (CFRD) [2]. This new type of dam is formed between RCCD and CFRD. Its section in the main body is basically symmetrical, which is made of cementitious materials, water, and riverbed gravel or excavation materials [3]. After cementitious materials and water are added to gravel or excavation materials, efficient earth-rock transport machinery and compaction machinery are used to shape the materials into CSGDs [4].

As a new model, CSGD is still evolving, and the research on dam safety is not systematic enough. According to statistics, since the 1980s, dozens of CSGDs have been built abroad, and relevant engineering exploration and practice have been carried out in Japan, Greece, Dominica, Philippines, Pakistan, Turkey, and other countries 
[5]. The application of CSGD in China began in 2004 in the upstream overflow cofferdam project of Daotang Reservoir in Guizhou Province. In this project, CSGD was adopted in China for the first time. The height of the cofferdam is $7 \mathrm{~m}$. Since then, CSGD technology was used in temporary construction such as downstream cofferdam of Jiemian Hydropower Station, upstream cofferdam of Hongkou Hydropower Station, and upstream cofferdam of Gongguoqiao Hydropower Station. On October 14, 2018, the filling of CSGDs was completed in Shoukoubao, Shanxi Province, with the maximum dam height of $61.6 \mathrm{~m}$. On June 7, 2019, the CSGD project of Jinjigou in Yingshan County of Sichuan Province was completed, with the maximum dam height of $33 \mathrm{~m}$, indicating that this dam type began to be applied in permanent projects.

The common methods of CSGD stress analysis include theoretical analysis, practical observation, numerical simulation, and model test [6-9]. It is very difficult to describe the failure process of CSGD with theoretical analysis of a single mathematical model [10]. The actual observation method is affected by many factors. It is hard to reproduce complex working conditions without perfect computational constitutive model for numerical analysis and practical engineering [11]. Compared with other research methods, physical model test has the advantage that the test conditions can be manually controlled and changed [12]. Therefore, physical model test is an effective method to study the stress distribution of CSGD [13], in which similar material selection is the most important part $[14,15]$. The model test data of cemented sand gravel is relatively scarce, and there are few reports on similar materials.

\section{Research Status of CSG Model Similar Materials}

Choosing the right and reasonable similar materials is key to accurately simulating the engineering prototype [14]. As modern testing technology and simulation theory keep developing, studies on model materials deepen and new model testing technologies (such as geomechanical model and centrifugal simulation technology) are successfully applied, and the research range of hydraulic structure model test further expands [15-18]. At present, the mainstream similar materials used for model tests in China are as follows: (1) MIB materials of high bulk density, low elastic modulus, and low strength, developed by Han Boli of Wuhan University [19, 20]; (2) NIOS materials developed by Li Zhongkui of Tsinghua University [21, 22]; and (3) iron barites sand cementation material (IBSCM) developed by Wang Hanpeng of Shandong University [23]. Organic materials such as oil, rosin, and alcohol and inorganic materials such as gypsum, water, and cement are used as binders for model materials [24]; copper powder, iron powder, iron concentrate powder, bentonite, sand, or diatomite are used as filling materials [25]; glycerol, rosin, alcohol, cooked starch slurry, and gypsum are used as additives [26]. Hydraulic structure model test has been developing in a more comprehensive way. However, as CSGD only has a short history and unique dam material properties, only a few research works at home and aboard have covered this material. The centrifuge modeling test was carried out by Chen Jiaojiao of Hohai University [27] to investigate the deformation of the dam model, while the materials used in the experiment to cast dam were consistent with the actual projects. There are many mechanical properties tests of cemented sand and gravel dam building materials in the existing research $[10,28,29]$, but the research on similar materials for model test of CSG dam is still not enough.

\section{CSG Similar Material Simulation Test}

3.1. Similarity Theory. The similarity theory is used to reveal the inherent relationship between similar physical phenomena and explore the fixed ratio between the physical quantities of the same name, and it is applied to scientific experiments and engineering and technical practice. Generally, the model test should satisfy the needs for geometric similarity and physical and mechanical similarity $[30,31]$ :

$$
\text { geometric similarity scale: }\left\{\begin{array}{l}
\text { length similarity constant } C_{L}=\frac{L_{p}}{L_{m}}, \\
\text { angular similarity constant } C_{\theta}=\frac{\theta_{p}}{\theta_{m}},
\end{array}\right.
$$




$$
\text { Physical similarity scale: }\left\{\begin{array}{l}
\text { stress similarity constant } C_{\sigma}=\frac{\sigma_{p}}{\sigma_{m}}, \\
\text { displacement similarity constant } C_{\delta}=\frac{\delta_{p}}{\delta_{m}}, \\
\text { Poisson's ratio similarity constant } C_{\mu}=\frac{\mu_{p}}{\mu_{m}} ; \\
\text { density similarity constant } C_{\rho}=\frac{\rho_{p}}{\rho_{m}}, \\
\text { strain similarity constant } C_{\varepsilon}=\frac{\varepsilon_{p}}{\varepsilon_{m}}, \\
\text { elastic modulus similarity constant } C_{E}=\frac{E_{p}}{E_{m}}, \\
\text { volumetric force similarity constant } C_{X}=\frac{X_{p}}{X_{m}}, \\
\text { bulk density similarity constant } C_{\gamma}=\frac{\gamma_{p}}{\gamma_{m}},
\end{array}\right.
$$

where $C$ is the similarity scale; $p$ is the prototype physical quantity; $m$ is the model physical quantity; $L$ is the length; $\theta$ is the angular displacement; $\sigma$ is the stress; $\delta$ is the displacement; $\mu$ is Poisson's ratio; $\rho$ is the density; $\varepsilon$ is the strain; $E$ is the elastic modulus; $X$ is the volumetric force; and $\gamma$ is the bulk density.

3.2. Similarity Relation. According to the equilibrium, geometric and physical equation, and boundary conditions of the similarity theory, the main loads for CSGD come from water pressure, uplift pressure, and dam body weight. Specifically, water pressure and uplift pressure act in the form of surface force, and gravity acts in the form of volume force. Then, based on dimensional analysis, similarity relation of CSGD model test can be obtained $[32,33]$ :

$$
\left\{\begin{array}{l}
C_{\mu}=C_{\varepsilon}=1 ; \\
C_{\gamma}=C_{\rho}, \\
C_{\sigma}=C_{\gamma} C_{L}=C_{E} C_{\varepsilon}, \\
C_{\varepsilon}=\frac{C_{\gamma} C_{L}}{C_{E}}, \\
C_{\delta}=\frac{C_{\gamma} C_{L}^{2}}{C_{E}}, \\
C_{F}=C_{\gamma} C_{L}^{3}=C_{E} C_{L}^{2} .
\end{array}\right.
$$

where $C_{\mu} C_{\gamma}, C_{\rho}, C_{\sigma}, C_{L}, C_{\varepsilon}, C_{E}, C_{\delta}, C_{F}$ refer to the abovementioned terms.

$$
\begin{aligned}
& \text { As } C_{\gamma}=1 \text {, then } \\
& \qquad \begin{array}{l}
C_{E}=C_{L}, \\
C_{F}=C_{L}^{3} .
\end{array}
\end{aligned}
$$

Because the aforementioned conditions are interrelated, the model has great difficulties in fully satisfying all of them. Based on the key points and characteristics of the research content, the model test can only satisfy the main similarity relationships and becomes basically similar to the prototype. Then, the test results are analyzed and selected.

3.3. Selection of Similar Materials. In general, the following requirements should be satisfied for selecting material similar to that of the model [34]: (1) According to the formula in the similarity theory, the bulk density of the model material should be the same as that of the prototype material. That is to say, when $C_{\gamma}=1$, the conversion between the physical parameters of the model and the prototype can be greatly simplified, and the effects of the gravity stress field can be better reflected. (2) The main physical and mechanical properties of the model material are equivalent to or close to the prototype material parameters after similar conversion. (3) The model material has good workability, which creates feasible conditions for molding, construction, and repair. (4) The physical, mechanical, chemical, and thermal properties of the model materials are stable and are less affected by the changes of time, temperature, and humidity.

In this test for the target, gravity similarity ratio $C_{\gamma}=1$, and geometric similarity ratio $C_{L}=100$. Given mechanical parameters and target similarity ratio of CSGD, the target parameters for preparing similar materials can be obtained, as shown in Table 1.

Based on the existing research results, the mechanical properties of SCG material have been simulated. In that test, coarse sand is chosen to simulate the prototype coarse 
TABle 1: Physicomechanical target parameters of the material.

\begin{tabular}{|c|c|c|c|c|c|c|}
\hline Parameters & $\begin{array}{l}\text { Bulk density } \\
\left(\mathrm{kN} / \mathrm{m}^{3}\right)\end{array}$ & $\begin{array}{l}\text { Elastic modulus } \\
(\mathrm{MPa})\end{array}$ & $\begin{array}{c}\text { Compressive strength } \\
(\mathrm{MPa})\end{array}$ & $\begin{array}{l}\text { Internal friction } \\
\text { angle } \varphi\left(^{\circ}\right)\end{array}$ & $\begin{array}{l}\text { Cohesion, } c \\
\quad(\mathrm{kPa})\end{array}$ & $\begin{array}{l}\text { Poisson's } \\
\text { ratio }(\mu)\end{array}$ \\
\hline $\begin{array}{l}\text { Prototype material } \\
\text { (Shoukoubao dam) }\end{array}$ & $22.8-26.3$ & $4500-5200$ & $8.2-15.1$ & $28-38$ & $476-710$ & 0.2 \\
\hline $\begin{array}{l}\text { Model material (conversion } \\
\text { value) }\end{array}$ & $22.8-26.3$ & $45-52$ & $0.08-0.15$ & $28-38$ & $4.76-7.1$ & 0.2 \\
\hline
\end{tabular}

aggregate, barite powder, as filler to simulate the prototype fine aggregate, and gypsum powder and cement, as cementitious materials. The strength of the material is controlled through changing the amount of gypsum and the ratio of water to gypsum. The elastic modulus of the material is changed by the amount of cement, and the bulk density of the model material is changed by choosing iron powder as the admixture. The excess water in the model material evaporates during the drying process, forming many tiny pores inside the gypsum block. This is the basis for simulating the pore characteristics of the prototype material.

3.4. Mix Design and Result Analysis. The four-factor and four-level orthogonal method was adopted for testing the model material test. Four factors were set up, namely, A, B, C, and D. Factor A refers to the ratio of iron powder content to total material content (\%); factor B, the ratio of gypsum content to total material content (\%); factor C, gypsum content/cement content; and factor D, coarse sand content/barite powder. In the process of mixing material, water is added in different stages (water consumption is determined by plasticity and fluidity of similar materials in the mixing process). Orthogonal design is detailed in Table 2.

In the model material test, 16 groups of orthogonal mixing schemes and 144 forming specimens were designed. In addition, the mechanical parameters of the model material were tested systematically and comprehensively. The results showed that when the iron powder content was $10 \%$, gypsum content was $20 \%$, gypsum: cement $=2: 1$, coarse sand $:$ barite powder $=3: 1$, and the material parameters of the model were closest to the test target value. The specific values and the test process are shown in Table 3 and Figure 1, respectively.

\section{Model Test of CSG Dam Body}

4.1. Model Scale Design. This dam model test took the prototype design of CSGD of Shoukoubao reservoir in Shanxi Province as a reference and carried out a generalized simulation, which is located in the upper reaches of Heishui River, with a geographic location of $113^{\circ} 40^{\prime} \mathrm{e}$ and $40^{\circ} 25^{\prime} \mathrm{n}$, about $10 \mathrm{~km}$ northwest of Yanggao County. Shoukoubao reservoir was started in April 2014 and was awarded as Technical Demonstration Project for Dam Construction with Cemented Granular Materials by General Institute of Water Conservancy and Hydropower Planning and Design, Ministry of Water Resources, in September 2017. The parameters of the prototype dam body are as follows: the maximum dam height was $61.6 \mathrm{~m}$, the width of the dam top was $6 \mathrm{~m}$, and the upstream and downstream slopes were $1: 0.6$. Cementitious materials are made of $50 \mathrm{~kg} / \mathrm{m}^{3}$ of cement material and $40 \mathrm{~kg} / \mathrm{m}^{3}$ of fly ash. The bulk density of the dam body was $23.5 \mathrm{kN} / \mathrm{m}^{3}$, the elastic modulus is $4.8 \mathrm{GPa}$, and Poisson's ratio is 0.20 ; the bulk density of the dam foundation was $20.2 \mathrm{kN} / \mathrm{m}^{3}$, with $7 \mathrm{GPa}$ of elastic modulus and 0.24 of Poisson's ratio. Based on the measurement requirements of model tests and engineering conditions, the dam foundation depth was simulated at $50 \mathrm{~m}$ in depth, about $0.8 \mathrm{H}$. The upstream simulation range was $30 \mathrm{~m}$, about $0.5 \mathrm{H}$, and the downstream simulation range was $150 \mathrm{~m}$, around $2.4 \mathrm{H}(\mathrm{H}$ is dam height). Model dam parameters were as follows: dam was $61.6 \mathrm{~cm}$ in height, and dam crest was $6 \mathrm{~cm}$ in width. In addition, both upstream and downstream slopes were 1 : 0.6. Dam foundation was simulated as $50 \mathrm{~cm}$ in depth. Upstream simulation range was $30 \mathrm{~cm}$, while downstream simulation range was $150 \mathrm{~cm}$. Then, the coordinates were set, with dam heel as the origin. According to the similarity relation, the similarity constants are shown in Table 4.

4.2. Modeling. Modeling includes the building of model groove and dam foundation, as well as dam body concreting and splicing. Dam body concreting and splicing should be carried out after model groove and dam foundation are built. The processes are introduced in detail [35-39] below.

(1) Preparation: coarse sand, barite powder, gypsum powder, cement, and iron powder were prepared in different masses, which were estimated based on the model size and the abovementioned mix ratio of model materials.

(2) Mixing: firstly, coarse sand, barite powder, and iron powder were weighed and poured into the mixing tank which mixed them evenly into aggregate. Secondly, gypsum powder and cement were added to the aggregate. Thirdly, a shovel was used to stir the mixed materials by lifting and dropping them 10-15 times, during which water was added. Water amount must be strictly controlled to prevent segregation. After fully mixing, the material was in a plastic state with fluidity. Finally, the material was poured into the preassembled mold to solidify.

(3) Drying and demolding: mold filled with material was carefully moved to the drying chamber. A far infrared heating plate of $20 \times 30 \mathrm{~cm}$ was used to bake the mold for 7 days. The temperature was strictly 
TABLe 2: Orthogonal design of similar materials.

\begin{tabular}{lcccc}
\hline Group & $\begin{array}{c}\text { Factor A } \\
\text { Iron powder content (\%) }\end{array}$ & $\begin{array}{c}\text { Factor B } \\
\text { Gypsum content (\%) }\end{array}$ & $\begin{array}{c}\text { Factor C } \\
\text { Gypsum: cement }\end{array}$ & $\begin{array}{c}\text { Factor D } \\
\text { Coarse sand: barite powder }\end{array}$ \\
\hline 1 & 5 & 10 & $1: 1$ & $1: 1$ \\
2 & 10 & 15 & $2: 1$ & $2: 1$ \\
3 & 15 & 20 & $3: 1$ & $3: 1$ \\
4 & 20 & 25 & $4: 1$ & $4: 1$ \\
\hline
\end{tabular}

TABle 3: Physicomechanical test parameters of the material.

\begin{tabular}{|c|c|c|c|c|c|c|}
\hline Parameters & $\begin{array}{l}\text { Bulk density } \\
\left(\mathrm{kN} / \mathrm{m}^{3}\right)\end{array}$ & $\begin{array}{c}\text { Elastic modulus } \\
(\mathrm{MPa})\end{array}$ & $\begin{array}{c}\text { Compressive strength } \\
(\mathrm{MPa})\end{array}$ & $\begin{array}{l}\text { Internal friction } \\
\text { angle }\left(^{\circ}\right)\end{array}$ & $\begin{array}{l}\text { Cohesion } \\
(\mathrm{kPa})\end{array}$ & Poisson's ratio \\
\hline $\begin{array}{l}\text { Prototype material } \\
\text { (Shoukoubao dam) }\end{array}$ & $22.8-26.3$ & $4500-5200$ & $8.2-15.1$ & $28-38$ & $476-710$ & 0.2 \\
\hline Model material (test value) & 23.5 & 46.02 & 0.11 & 32 & 5.12 & 0.2 \\
\hline
\end{tabular}

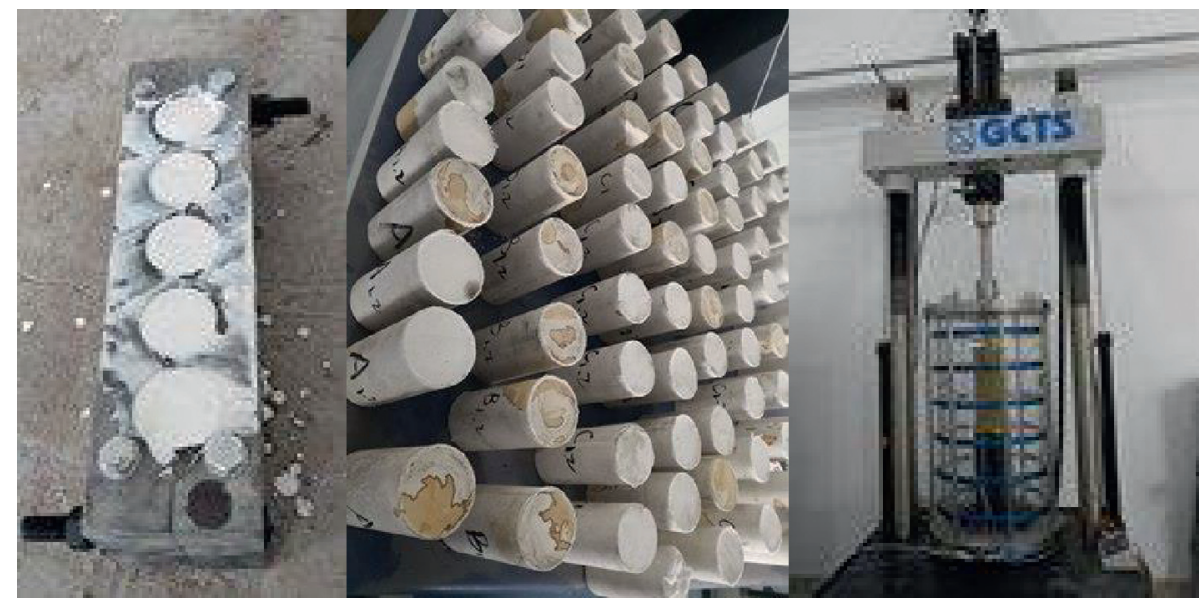

FIgURE 1: Model similar material testing process.

TABLe 4: Model similarity parameter table.

\begin{tabular}{lcccccccccccc}
\hline $\begin{array}{l}\text { Similarity } \\
\text { constant }\end{array}$ & $\mathrm{C}_{L}$ & $C_{\mu}$ & $\mathrm{C}_{\gamma}$ & $\mathrm{C}_{\varepsilon}$ & $\mathrm{C}_{f}$ & $\mathrm{C}_{c}$ & $C_{\sigma}$ & $\mathrm{C}_{E}$ & $\mathrm{C}_{\delta}$ & $C_{F}$ \\
\hline Value & 100 & 1 & 1 & 1 & 1 & 1 & 100 & 100 & 100 & $100^{3}$ \\
\hline
\end{tabular}

Note. The meaning of each symbol is as mentioned above.

controlled between $40^{\circ} \mathrm{C}$ and $45^{\circ} \mathrm{C}$ to ensure the mold was heated evenly as too high temperature will lead to dehydration and powdery surface. What is more, if the temperature becomes too high, strength and elastic modulus of the newly formed blank will be reduced significantly, which will affect the measurement results. After drying, the blank can be demolded.

(4) Polishing and molding: after demolding, the blank was larger than the dam model, and its surface was attached with a hard shell (consisting of oil, dust, etc.). Therefore, it needs to be polished manually or mechanically before connecting with the dam foundation. The surface smoothness of the model was corrected repeatedly with the prefabricated sample. The accuracy was controlled at $\pm 3 \mathrm{~mm}$ to ensure the accuracy of the subsequent loading measurement. The fabrication of dam body mold is shown in Figure 2.

4.3. The Model Measurement System and Loading. The measurement system in the dam model test comprised strain measurement and displacement measurements. The strains and displacement of the dam body surface were monitored with resistance strain gauges and displacement digital display instruments, respectively. Three rows of strain measuring points, numbered 1-9, 10-18, and 19-23, were arranged at the dam bottom, 1/3 dam height and $1 \mathrm{~cm}$ near the dam bottom, respectively. The same measuring points were also arranged on the back of the model at the same time as objects of reference. Each measuring point was equipped with a strain gauge rosette containing three resistors at $45^{\circ}$ relative orientations, and a compensator was set up to eliminate the temperature effect. Vertical displacement sensors whose numbers were No. 1, No. 3, No. 5, and No. 7, respectively, and horizontal displacement sensors whose numbers were No. 2, No. 4, No. 6, and No. 8, respectively, were installed on the dam crest on the downstream face, at 2/3 dam height, 1/3 dam 


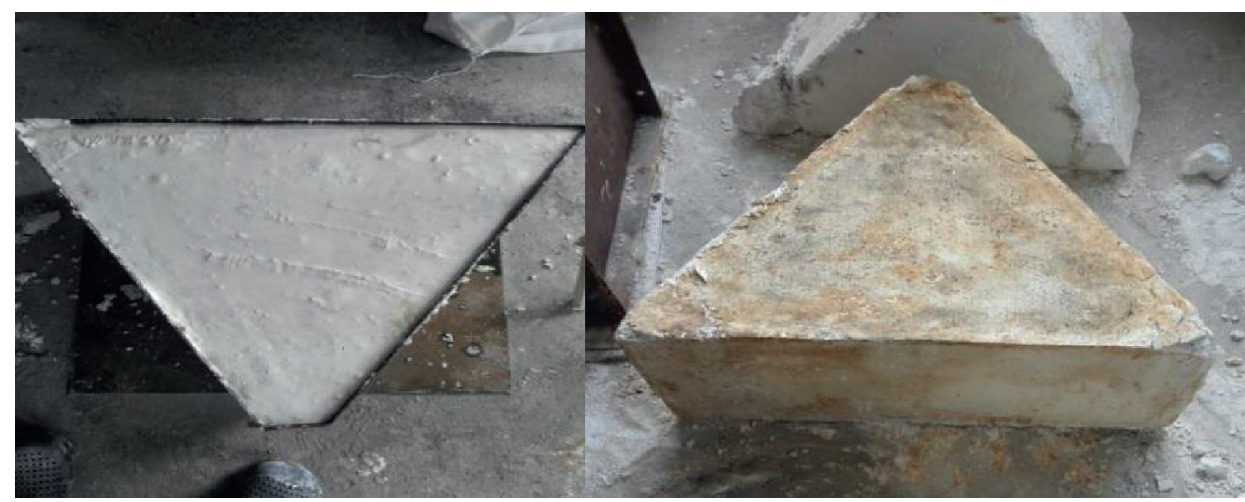

Figure 2: Dam body molds.

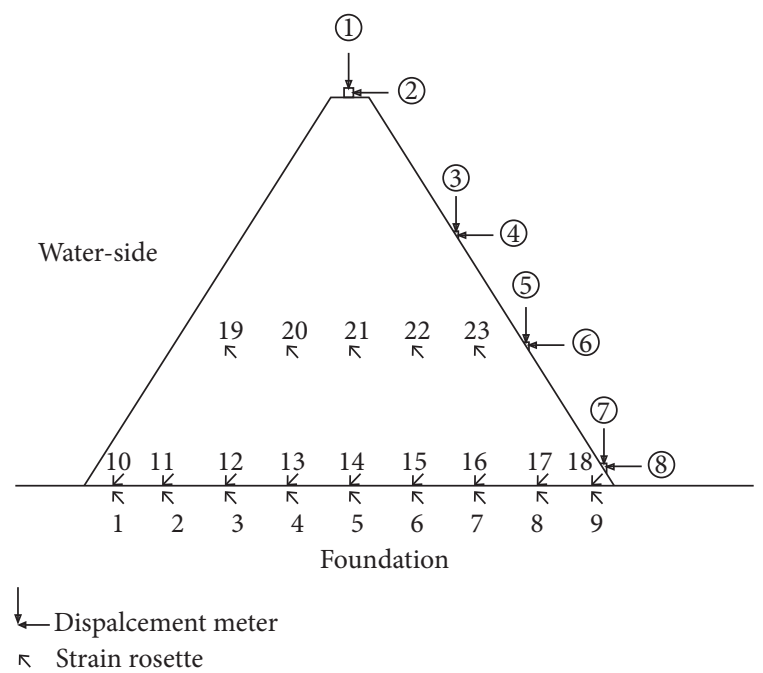

FIGURE 3: Measurement system.

height, and the toe of the dam, respectively, as shown in Figure 3.

This test simulated the water pressure and the self-weight of the dam as main loads, without considering the seepage field and the seismic load. Among the loads considered, the upstream normal water level was taken as the water pressure, and the self-weight was simulated by ensuring that the prototype material had the same volume density as the dam material [40]. Three jacks were used to act vertically on the steel plate, which was flat against the dam surface to transform the point loads of the jacks into the surface load on the upstream face of the dam, as shown in Figure 4.

4.4. Test Results and Analysis. The dam model test contained two periods: the construction simulation and the normal operation simulation. During the construction period, the dam was divided into four layers and placed layer by layer to monitor the stress of the dam foundation and body, considering only the dam gravity. As the water pressure was an additional factor during the normal operation period, the dam layers during the construction period were closely bonded with polymer cementing materials (model 1\#), and the whole load was applied to measure the stress and displacement of the dam foundation and the dam body. In addition, a comparison model (model 2\#)

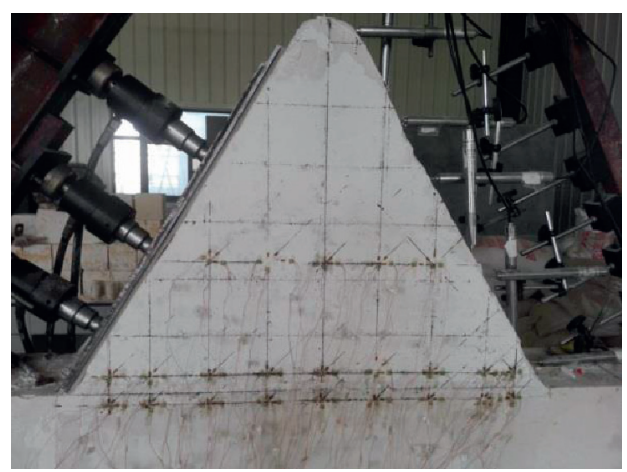

Figure 4: Loading system.

was made using overall pouring to verify the data. The stress value was positive in compression and negative in tension, the horizontal displacement was positive downstream, and the vertical displacement was positive upstream [41].

4.4.1. Stress Measurement during Construction. The dam stress during the construction period was obtained after the measured data were processed based on the measurement scale of the model, as shown in Figure 5.

The test results show the following: (1) during the construction period, the stress of dam foundation, dam bottom, and dam center was very small. The maximum stress of the dam was found in the middle of the dam bottom, which was less than $0.6 \mathrm{MPa}$, about $1 / 14-1 / 25$ of the designed compressive strength of the dam material. (2) The stress of the dam body and the foundation increased as the construction height rose. For the dam body, the stress was identified as compressive stress. Tensile stress appeared near the toe and heel of the dam, but the value was very small. (3) At different elevations, the stress was distributed symmetrically around the axis of the dam. The reasons were analyzed by simulating the construction process of CSGD. The construction period is only affected by the gravity of the dam body. It turned out that the construction period was only affected by the selfweight of the dam body, while the profile of the dam body was designed to be symmetrical and the stress was uniform. As a result, only compressive stress was generated 


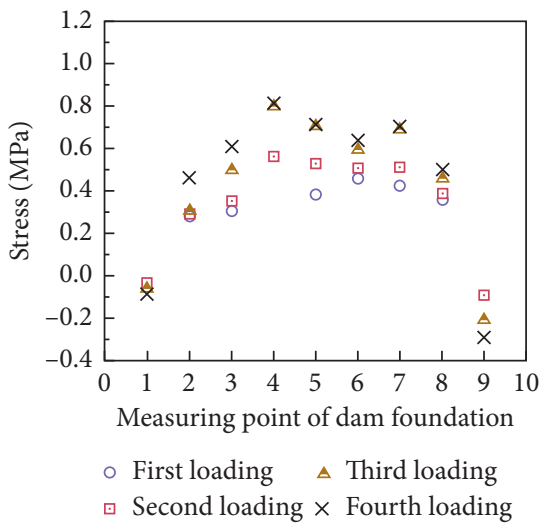

(a)

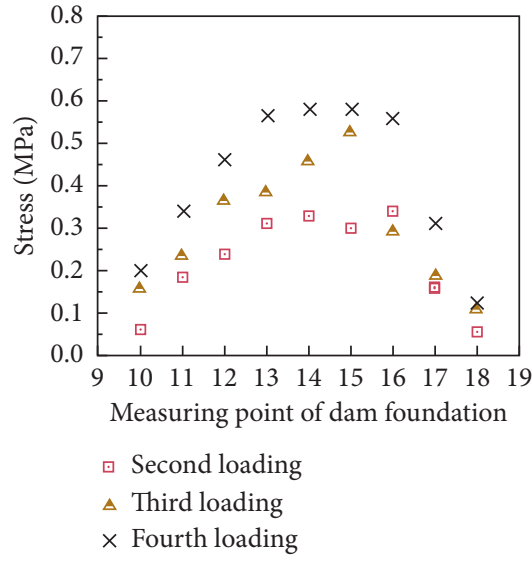

(b)

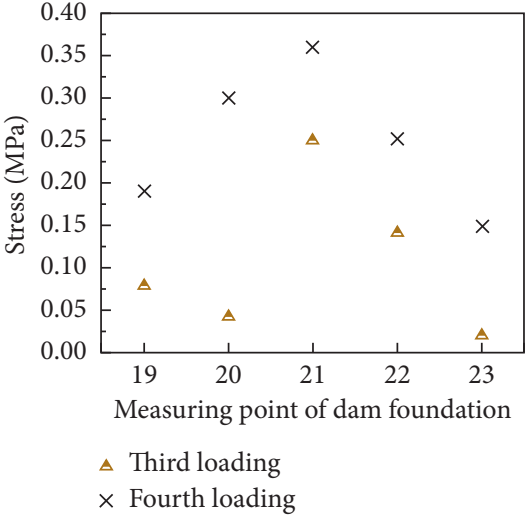

(c)

FIGURE 5: Stress survey map during construction period.

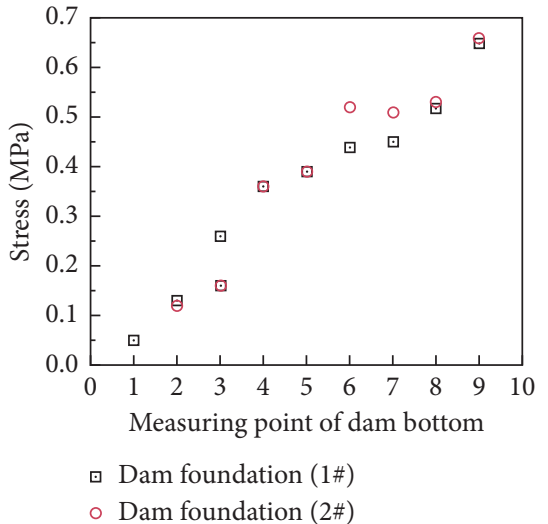

(a)

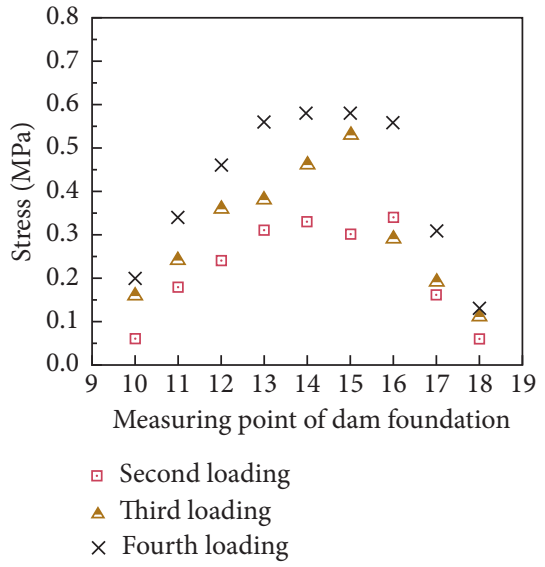

(b)

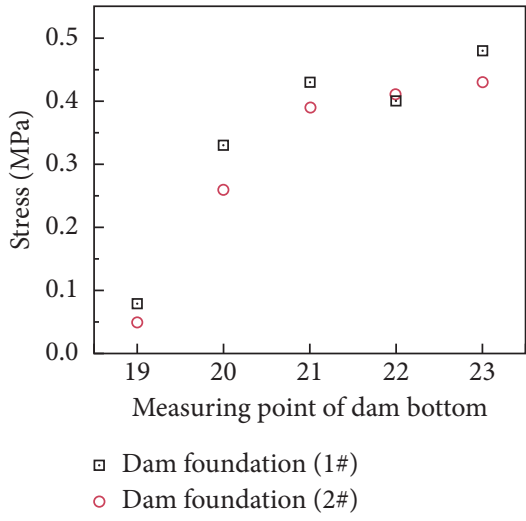

(c)

FIgURE 6: Stress survey map during normal operation period.

inside the dam body. The gravity of the dam body caused slight settlement deformation of the dam foundation, and the created tensile stress appeared near the toe and heel of the dam, which were both within the allowable range [42].

4.4.2. Stress Measurements and Displacement Measurements during Normal Operations. The measured data were processed according to the measurement scale of the model. The stress of the dam body in the normal operation period was obtained by excluding the data of the self-weight influence on the dam body and dam foundation in the process of layered loading, keeping only the data of the dam body under water load, as shown in Figure 6 (1\#: cemented dam body, 2\#: overall pouring). The dam displacement during the normal operation period is presented in Figure 7.

The test results indicate the following: (1) The slight and consistently distributed differences of stress between consolidated model (1\#) and overall casting model (2\#)

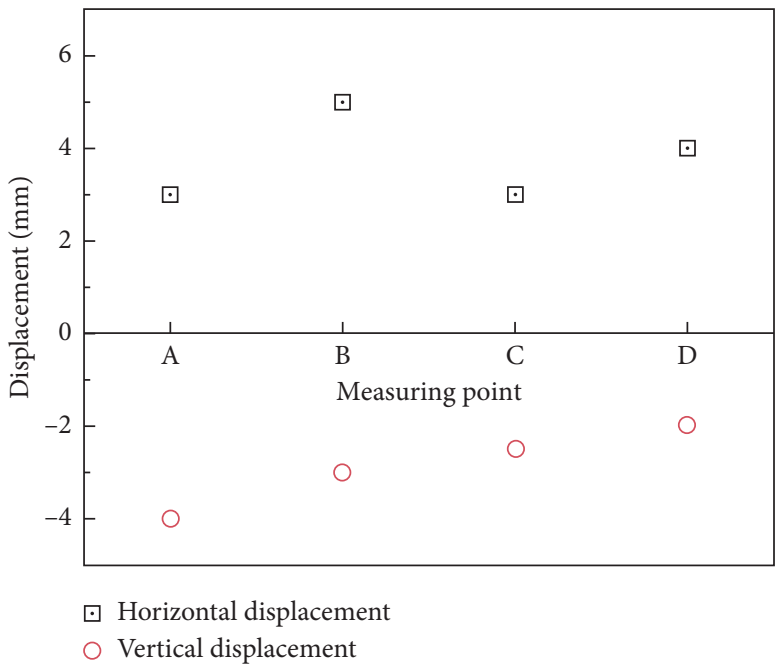

FIgURE 7: Displacement survey map during normal operation period. 
under normal operation show that the impact of the layered and graded loading simulation construction on dam body and foundation is rational. (2) Compressive stress, the stress undertaken by the foundation and the body of the model dam, generally peaks when measured at the bottom of the dam and reaches the maximum level (less than $0.9 \mathrm{MPa}$ ) in the downstream of the dam bottom, ranging from $1 / 9$ to $1 / 17$ of the designed compressive strength of dam material. (3) The stress distribution of dam foundation and dam body under operation is totally different from that under construction. The stress distribution increases gradually from upstream to downstream at the same elevation, while the stress distribution of dam body decreases gradually from bottom to top if measured at different elevations. The analysis shows that self-weight and water load, vertical to the upstream surface, are the main sources of stress compressing the dam body. Meanwhile, the section of the dam is designed to be symmetrical, so the stress is distributed evenly as the self-weight of the dam body counteracts the tensile stress on the dam heel from the water load [43].

The distribution law of displacement: Under the pressure of water load and self-weight, the whole dam body deforms horizontally towards the downstream, with the maximum deformation at $2 / 3$ height of the dam; vertically, the dam has settlement deformation with the maximum deformation at $0.65 \%$ of the dam height at the top of the dam.

The stress level of the body and the foundation of the model dam are too low under the two abovementioned construction conditions where the potential of material strength cannot be fully realized, and the section design can be further optimized. When operating normally, the deformation of dam body is even slighter than that of dams built with similar materials. Therefore, CSGD proved to be a safe new type of dams [44].

\section{Conclusions}

This paper takes CSGD in Shoukoubao, Shanxi Province, as a prototype to introduce in detail the similarity principle of model test and describe the selection steps of CSG model. The material similar to the one used in CSG dam for the model has been developed as a mix of coarse sand, barite powder, gypsum powder, cement, and iron powder. The model-based tests of dam body have studied the two working conditions of construction and normal operation. The main conclusions obtained were as follows:

(1) As the results of extensive experiments show, the physical and mechanical parameters of the model material are the closest to the target value of the prototype when the iron powder content is $10 \%$, gypsum content is $20 \%$, gypsum: cement $=2: 1$, and coarse sand: barite powder $=3: 1$.

(2) The maximum stress of dam body, found at the center of the bottom during construction, is about $1 / 14-1 / 25$ of the designed compressive strength of dam body material, distributed symmetrically on both sides of the axis of the dam. When operating, the stresses of the foundation and the body of the model dam are compressive stresses which generally peak when measured at the bottom of the dam and reach the maximum level in the downstream of the dam bottom, ranging from $1 / 9$ to $1 / 17$ of the designed compressive strength of the dam material.

(3) The stress distribution increases gradually from upstream to downstream at the same elevation, while the stress distribution of dam body decreases gradually from bottom to top if measured at different elevations. Under the pressure of water load and selfweight, the whole dam body deforms horizontally towards the downstream, with the maximum deformation at $2 / 3$ height of the dam; vertically, the dam suffers settlement deformation with the maximum deformation at $0.65 \%$ of the dam height at the top of the dam.

(4) The stress level of the body and the foundation of the model dam are too low under the abovementioned two construction conditions where the potential of material strength cannot be fully realized and the section design can be further optimized. Therefore, CSGD proved to be a safe new type of dams. In addition, taking the nature of discreteness of CSG material into consideration, further research should be conducted to solve issues including upgrading simulation when selecting model materials and the method to load the internal seepage field in the process of dam model experiment.

\section{Data Availability}

The data used to support this study are included within the article.

\section{Conflicts of Interest}

The authors declare that there are no conflicts of interest regarding the publication of this paper.

\section{Acknowledgments}

The authors would like to acknowledge the financial support received from the National Key Research and Development Program of China (2018YFC0406803) and Foundation for University Key Teacher by Henan Province of China (2019GGJS009).

\section{References}

[1] P. Londe and M. Lino, "The faced symmetrical Hard-fill dam: a new concept for RCC," International Water Power \& Dam Construction, vol. 44, no. 2, pp. 19-24, 1992.

[2] J. S. Jia, F. L. Ma, X. Y. Li et al., "Study on material characteristics of cemented sand-gravel dam and engineering application," Journal of Hydraulic Engineering, vol. 37, no. 5, pp. $578-582,2006$.

[3] M. A. Stevens and J. Linard, "The safest dam," Journal of Hydraulic Engineering, vol. 128, no. 2, pp. 139-142, 2002. 
[4] J. S. Jia, N. Liu, C. Y. Zheng et al., "Research on progress and engineering application of cemented granular material dam," Journal of Hydraulic Engineering, vol. 47, no. 3, pp. 315-323, 2016.

[5] J. M. Peter, "Hardfill and the ultimate dam," Hydro Review Worldwide, vol. 6, no. 11, pp. 26-29, 2004.

[6] S. Batmaz, "Cindere dam-107m high roller compacted Hardfill dam (RCHD) in Turkey," in Proceedings of the 4th International Symposium on Roller Compacted Concrete Dams, pp. 121-126, Madrid, Spain, 2003.

[7] T. Hirose, T. Fujisawa, H. Yoshida et al., "Concept of CSG and its material properties," in Proceedings of the 4th International Symposium on Roller Compacted Concrete Dams, pp. 465-473, Madrid. Spain, 2003.

[8] T. Fujisawa, A. Nakamura, H. Kawasaki et al., "Material properties of CSG for the seismic design of trapezoid-shaped CSG dam," in Proceedings of the 13th World Conference on Earthquake Engineering, pp. 391-394, Vancouver, Canada, 2004.

[9] L. Kongsukprasert, F. Tatsuoka, and M. Tateyama, "Several factors affecting the strength and deformation characteristics of cement-mixed gravel," Soils and Foundations, vol. 45, no. 3, pp. 107-124, 2004.

[10] T. N. Lohani, L. Kongsukprasert, K. Watanabe, and F. Tatsuoka, "Strength and deformation properties of compacted cement-mixed gravel evaluated by triaxial compression tests," Soils and Foundations, vol. 44, no. 5, pp. 95-108, 2004.

[11] L. Kongsukprasert, Y. Sano, and F. Tatsuoka, "Compaetionindueed anisotropy in the strength and deformation characteristics of cemen-mixed gravelly soils," Soil Stress-Strain Behavior: measurement, Modeling and Analysis, pp. 479-490, Springer, Dordrecht, Netherlands, 2006.

[12] P. J. Mason, R. A. N. Hughes, and J. D. Molyneux, "The design and construction of a faced symmetrical Hardfill dam," International Journal on Hydropower and Dams, vol. 15, no. 3, pp. 90-94, 2008.

[13] Z. Tokmechi, "Structural safety studies of Klahir dam in Iran," Middle-East Journal of Scientific Research, vol. 6, no. 5, pp. 500-504, 2010.

[14] M. Q. Sun, S. F. Yang, and Q. Q. Tian, "Summary of research on mechanical properties, durability and dam type of cemented sand and gravel material," Yellow River, vol. 7, pp. 83-85, 2016.

[15] Q. H. Chai, M. Q. Sun, and S. F. Yang, "Study on influencing factors of compressive strength of cemented sand and gravel materials," Yellow River, vol. 7, pp. 86-88, 2016.

[16] H. C. Yang, Structural Design and Engineering Application of Cemented Sand and Gravel Dam, China Institute of Water Resources and Hydropower Research, Beijing, China, 2013.

[17] Z. J. Yue, The Working Characteristics of Cemented Sand and Gravel Dam on Different Foundation, Wuhan University, Wuhan, China, 2005.

[18] H. B. Nie, J. H. Dong, and L. Zhang, "Study on destroy mode and stability of Hardfill dam under different foundation conditions," Journal of Sichuan University (Engineering Science Edition), vol. 47, no. S1, pp. 36-40, 2015.

[19] B. L. Han, Y. H. Gu, and M. X. Song, "Study on triaxial stress characteristics of several model materials," Engineering Journal of Wuhan University, vol. 1, no. 1, pp. 3-11, 1984.

[20] B. L. Han, X. L. Chen, Y. L. Song et al., "Research on similar material of rock mass," Engineering Journal of Wuhan University, vol. 30, no. 2, pp. 6-9, 1997.
[21] F. P. Ma, Z. K. Li, and G. F. Luo, "NIOS model material and its use in geomechanical similarity model test," Journal of Hydroelectric Engineering, vol. 23, no. 1, pp. 48-51, 2004.

[22] Q. Y. Zhang, S. C. Li, and Y. Y. Jiao, Rock Mass Numerical Analysis Method and Geomechanics Model Test Principle and Engineering Application, China Water Power Press, Beijing, China, 2005.

[23] H. P. Wang, S. C. Li, Q. Y. Zhang et al., "Development of a new geomechanical similar material," Chinese Journal of Rock Mechanics and Engineering, vol. 25, no. 9, pp. 1842-1847, 2006.

[24] J. Y. Chen, L. Zhang, and Y. Chen, "Failure model test on deep anti-sliding stability of Wudu RCC gravity dam," Chinese Journal of Rock Mechanics and Engineering, vol. 26, no. 10, pp. 2097-2103, 2007.

[25] B. Q. Yang, L. Zhang, J. Y. Chen et al., "Experimental study of 3D geomechanical model for global stability of Xiaowan high arch dam," Chinese Journal of Rock Mechanics and Engineering, vol. 29, no. 10, pp. 2086-2093, 2010.

[26] Z. L. Ding, L. Zhang, X. L. Yao et al., "Failure experimental study on stability of high arch dam on complex foundation," Journal of Sichuan University (Engineering Science Edition), vol. 42, no. 6, pp. 25-30, 2010.

[27] J. Chen, X. Cai, E. Lale, J. Yang, and G. Cusatis, "Centrifuge modeling testing and multiscale analysis of cemented sand and gravel (CSG) dams," Construction and Building Materials, vol. 223, pp. 605-615, 2019.

[28] X. Cai, Y. L. Wu, H. X. Li et al., "Constitutive equation for CSG materials," Chinese Journal of Geotechnical Engineering, vol. 32, no. 9, pp. 1340-1344, 2010.

[29] X. Cai, J. Yang, X. W. Guo et al., "A new type of nonlinear K-G-D constitutive model for CSG material," Journal of Hohai University(Natural Sciences), vol. 42, no. 6, pp. 41-42, 2014.

[30] Z. L. Ding, L. Zhang, Y. Chen et al., "3D geo-mechanical model failure test on stability against deep sliding of gravity dam," Journal of Hydraulic Engineering, vol. 42, no. 4, pp. 499-504, 2011.

[31] K. Xiong, Y. L. He, and W. Wu, "Study on structure failure test of hardfill dam," Journal of Hydraulic Engineering, vol. 43, no. 10, pp. 1214-1222, 2012.

[32] Z. L. Ding, S. F. Yang, and M. Q. Sun, "Model test of cemented sand and gravel dam," Yellow River, vol. 38, no. 9, pp. 92-95, 2016.

[33] X. T. Cui, Z. D. Zhang, and S. Fan, "Research on mechanical model test materials Based on the similar theory," Pearl River, vol. 40, no. 5, pp. 82-86, 2019.

[34] X. Y. Geng and Z. X. Zhang, "Study on preparation methods for similar materials of sandstone," Chinese Journal of Underground Space and Engineering, vol. 11, no. 1, pp. 23-28, 2015.

[35] Z. V. Chen, J. Wu, J. R. Zhang et al., "Preparation of similar materials of the surrounding rock in model test," Modern Tunnelling Technology, vol. 55, no. S2, pp. 102-107, 2018.

[36] Y. Q. Yang, T. N. Xue, T. C. Li et al., "Comparison research on materials similar to bolt in model test," Mining Research and Development, vol. 38, no. 8, pp. 81-83, 2018.

[37] J. Yao, J. Li, and X. Huang, "Experimental study on mia proportion of similar material for weathered mudstone," Modern Tunnelling Technology, vol. 55, no. 2, pp. 1069-1079, 2018.

[38] S. L. He, X. Huang, and Z. X. Zhang, "Study on the mechanical properties of gypsum specimens," Chinese Journal of Underground Space and Engineering, vol. 12, no. 1, pp. 49-55, 2016. 
[39] J. Y. Dong, J. H. Yang, G. X. Yang et al., "Research on similar material proportioning test of model test based on orthogonal design," Journal of China Coal Society, vol. 37, no. 1, pp. 44-49, 2012.

[40] X. Yang, D. L. Su, B. Zhou et al., "Experiment study on similarity ratio of similar material for model test on red-bed soft rock," Rock and Soil Mechanics, vol. 37, no. 8, pp. 2231-2237, 2016.

[41] X. L. Zhang, "Test research on construction technique parameters of cemented sand and gravel dam at the Datong Shoukoupu Reservoir," Shanxi Hydrotechnics, vol. 11, no. 4, pp. 103-105, 2015.

[42] J. H. Cao, "Test and analysis of shear strength of contact surface of cemented sand and gravel cushion in Shoukoubu reservoir's Dam," Shanxi Hydrotechnics, vol. 8, no. 3, pp. 77-79, 2017.

[43] J. Y. Yang, H. Y. Yan, and J. Y. Wang, "Design of cemented sand and gravel dam of Shoukoupu Reservoir," Technical Progress in Construction and Operation Management of High Dams-CHINCOLD Collected Papers of the 2014 Annual Academic Conference, pp. 561-568, Yellow River Water Conservancy Press, Zhengzhou, China, 2014.

[44] W. J. Song, "Experimental study on cemented sand and gravel dam construction in Shoukoubao Reservoir," China Water Power \& Electrification, vol. 1, no. 1, pp. 49-51, 2017. 